\title{
Trauma and amputations in 19th century miners from Kimberley, South Africa
}

\author{
A.E. Van der Merwe ${ }^{1,2}$, M. Steyn ${ }^{1}$, E.N. L’Abbé ${ }^{1}$ \\ ${ }^{1}$ Department of Anatomy, University of Pretoria, Pretoria, South Africa \\ ${ }^{2}$ Department of Anatomy and Embryology, Leiden University Medical Centre, Leiden, \\ Netherlands
}

Corresponding author: A.E. Van der Merwe

Tel: +31(0)71 5269317

Fax: $+31(0) 71-526.8289$

Email: A.E.van_der_Merwe@lumc.nl

Postal address: Dept. of Anatomy \& Embryology

Leiden University Medical Center

PO BOX 9600, 2300 RC,

Leiden

The Netherlands 


\begin{abstract}
Trauma is the result of violent, accidental or therapeutic events that cause physical or psychological injury. The frequencies and types of trauma within a population can give important information regarding their lifestyle as well as the quantity and quality of medical care available to them. The purpose of this study was to assess the incidence of trauma in the Gladstone sample population with regards to the presence of interpersonal violence, a hazardous working environment, strenuous working requirements and the availability of medical care. The individuals studied here were diamond miners from Kimberley, dating to the late $19^{\text {th }}$ century. A total of 107 well preserved skeletons were excavated from unmarked graves after accidental discovery. This sample included 86 males, 15 females and 6 individuals of unknown sex. The majority of individuals (71\%) were between 19 and 45 years of age. The remains were most likely those of migrant mine workers of low socio-economic status who had passed away at the local hospitals. All bones were visually assessed for macroscopic indications of traumatic bone alterations and compared to standard palaeopathological texts and photographs. A total of $27 \%(n=28)$ of the individuals in the sample presented with well-healed, healing or perimortem fractures. Fractures to the skull encompassed $49 \%(n=20)$ of all the fractures that were observed. A total of six (6\%) amputations were noted. Spondylolysis was observed in $7 \%(n=7)$ of the individuals within the sample and longstanding subluxation was noted in two individuals. The high incidences of cranial fractures within this population are suggestive of high levels of interpersonal violence, while long bone fractures, spondylolysis and evidence of longstanding subluxations are indicative of the strenuous work requirements and the highrisk environment to which these individuals were exposed. When considering the presence of well-reduced fractures and healed amputations, it seems that adequate medical care was available to at least some members of this community.
\end{abstract}

Keywords: Skeletal trauma, fractures, amputations, spondylolysis, Kimberley, Palaeopathology 


\section{Introduction}

Diamonds were first discovered on the Colesberg Kopje (today known as the "big hole"in Kimberley, South Africa) in 1871. By August that year approximately 800 claims had been cut out of Colesberg Kopje and between 2000 and 3000 men were working there (Roberts, 1976). Colesberg Kopje was soon to become Kimberley, the first large inland settlement in South Africa to be developed away from a natural water source. Kimberley was the first town in South Africa to be completely dependant on mineral wealth, the first to experience a strike, and the first town to have its streets lit by electricity (Roberts, 1976).

During the late $19^{\text {th }}$ century, historical documents indicate that "Native" individuals flooded into Kimberley from surrounding areas and neighbouring countries in search of work on the mines (Stoney, 1900). A census was held in 1898 and it was established that there were approximately 14500 Europeans and 26500 Black labourers living and working in Kimberley (Stoney, 1900). The number of Black labourers in Kimberley were extremely changeable and dependant on the demand for labour in the mines (Stoney, 1900; McNish, 1970; Jochelson, 2001). Black labourers "from almost every tribe south of the Zambezi" (Roberts, 1976: 15) were brought to Kimberley to work, and when their contract expired, returned to their "kraals" (McNish, 1970; Leary, 1891; Roberts, 1976:294).

Mining was a labour- intensive task, fresh fruit and vegetables were scarce, comfortable accommodation was restricted and medical care limited. All of these factors contributed to the high incidence of disease and injury described in archival documents from Kimberley Hospital (Cape of Good Hope Votes and Proceedings of Parliament, 1899; Stoney, 1900; Roberts, 1976; Van der Merwe, 2007).

Labourers received medical attention from the Kimberley and compound hospitals. In the case of death, the patient was wrapped in blankets and received a pauper's burial, without a coffin at the Gladstone or other surrounding cemeteries (Swanepoel, 2003).

The Gladstone cemetery was officially opened on the $24^{\text {th }}$ of March 1883 in which half of the ground was devoted to African burials. Nearly 5000 African individuals were buried at the Gladstone cemetery between June 24, 1887 and November 28, 1892. Unfortunately, no registers were available for the period between 1892 and 1900. However, some 
documents indicate that a total of 611 pauper burials took place between February and June 1900 (Swanepoel, 2003).

In 1897, Gladstone cemetery was enlarged with an extra strip of land, given by the De Beers mining company, on the eastern side (Figure 1) of the cemetery. The cemetery was closed in mid-1900, and opened again in April 1902 for European internments only. In 2003, the Sol Plaatjie municipality uncovered several unmarked graves in the abovementioned eastern area, these remains became the focus point of this research in which traumatic injuries of diamond mine workers was assessed.

Trauma is the result of intentional or accidental encounters with animals, humans, and cultural hazards found in and around the home and working place, or therapeutic procedures that cause injury to a person (psychologically or physically) (Merbs, 1989; Lovell, 1997;Walker, 2001; Neri \& Lancellotti, 2004). The assessment of the prevalence of trauma in an archaeological population is difficult to interpret, since the investigation of dry bone poses several limitations. Determining trauma frequency rates is often hindered by poor preservation and fragmentation of skeletal remains. Perimortem trauma often mimics post depositional damage and consequently passes undetected. This is also the case in well remodelled fractures (Grauer \& Roberts, 1996).

Notwithstanding the limitations, the assessment of trauma within a population can still yield considerable information (Ortner, 2003). The prevalence and location of traumatic lesions are influenced by intrinsic factors such as age and sex, as well as extrinsic factors relating to culture (Glencross \& Stuart-Macadam, 2000; Lovell, 1997; Ortner, 2003). Different environmental conditions and cultural practices expose individuals to specific traumatic hazards. Therefore, the study of the prevalence of trauma within a population can aid in reconstructing the occupational and environmental stresses the sample was exposed to, as well as various aspects of cultural behaviour (Steinbock, 1976; Jurmain \& Bellifemine, 1997; Kilgore et al., 1997; Lovell, 1997; Ortner, 2003). By determining whether the fracture is healed, unhealed or infected, conclusions can be made regarding the availability of medical care and the accommodation of injured individuals within the community (Steinbock, 1976; Kilgore et al., 1997; Neri \& Lancellotti, 2004). 
The purpose of this study was to assess the incidence of trauma in the skeletal population exhumed from the Gladstone cemetery. The prevalence, nature and location of fractures, amputations and longstanding subluxations will be interpreted and discussed with regard to the availability of medical care at the close of the $19^{\text {th }}$ century, levels of interpersonal violence and exposure to a hazardous working environment (i.e. mining).

\section{Materials and Methods}

In April 2003, numerous unmarked graves were disturbed outside the fenced Gladstone cemetery. The McGregor Museum in Kimberley was given permission by the South African Heritage Resources Agency (SAHRA) to exhume and investigate the human remains.

The remains are believed to be those of migrant mine workers who passed away at the surrounding hospitals in Kimberley between 1897 and 1900 (Van der Merwe, 2007). These individuals were of low socio-economic status, malnourished, and exposed to a high pathogen load (Van der Merwe, 2007). The low socio-economic status of these individuals was clearly illustrated by their burial positions with the majority of persons being laid to rest without coffins and in graves containing more than one individual.

Standard anthropometric techniques such as morphological changes of the sternal ends of the ribs, changes to the pubic symphysis, cranial suture closure as well as cranial and pelvic morphology and discriminant functions were used to determine the age and sex of all individuals exhumed from the trench (e.g., De Villiers, 1968; Krogman \& İşcan, 1986; Hillson, 1998; Oettlé \& Steyn, 2000; Asala, 2001; Franklin et al., 2005).

A total of 86 males, 15 females and 6 individuals of unknown sex were excavated from the trench. The majority of these individuals (71\%) were between 19 and 45 years of age, while the rest comprised of one premature baby, two infants (both younger than one year of age), eight juveniles (11 - 19 years) and 10 individuals older than 45 years of age. Due to the fragmentary condition of some of the remains investigated in this study, eight individuals could only be described as being adult and two were of unknown age. With the 
exception of the last mentioned 10 skeletons, all others were remarkably well preserved and complete.

All bones were visually assessed for macroscopic indications of traumatic bone alterations and diagnoses were made based on the bony characteristics of these defects. All lesions were compared to standard palaeopathological texts and photographs as can be found in Steinbock (1976), Roberts and Manchester (1995), Mann and Murphy (1996), Larsen (1997), Aufderheide and Rodríguez-Martin (1998) and Ortner (2003). X-rays were not part of the routine investigation due to time and financial constraints.

Special attention was also given to distinguish between perimortem trauma and damage caused to the remains by the trenching machinery. Perimortem fractures were identified by the absence of signs of healing. Fracture lines are generally sharp and smooth and associated with radiating lines (hairline fractures) at the site of trauma. The fractured ends are also as discoloured and weathered as the adjacent bone, and it could thus be determined whether unhealed fractures were the result of damage by the trenching machinery or perimortem trauma (Steinbock 1976; Roberts and Manchester, 1995; Mann and Murphy, 1996; Ortner, 2003).

The prevalence of skeletal lesions indicative of trauma was determined in relation to the number of individuals within the sample population, as well as the number of bony elements investigated. These frequencies were compared to other studies conducted in South-Africa and Northern Chile. (Eisenstein, 1978; Standen \& Arriaza, 2000). Chisquared tests were carried out in order to compare the prevalence of traumatic lesions between these comparative groups and the Gladstone sample. Chi-squared tests were also performed in order to test for significant differences in the frequency of lesions between males and females, where possible. 


\section{Results}

\section{Fractures}

A total of $27 \%(n=28)$ of the individuals excavated from the trench (Table 1$)$ presented with well-healed, healing or perimortem fractures. Twenty-four of these were male and four female. No significant difference could be found in the frequency of fractures between the sexes $\left(\chi^{2}=0.006\right.$, p-value $\left.>0.2\right)$.

A total of 36 fractured bones were observed (Table 2). These included 15 fractured crania, five femoral fractures, four fractured ribs, two fractured fibulae, radii, ulnae and claviculae as well as one fractured tibia, os coxa, humerus and vertebra. It is clear that the majority of fractures occurred on the skulls, with $18 \%$ of crania presenting with a lesion (s).

Single fractures were noted in 19 individuals, while six people had two fractures, two had three fractures each, and one male had a total of four fractures. A summary of this information can be seen in Table 3 .

Eight perimortem fractures were observed in five skeletons. Several well-healed and remodelled fractures were also noted. These included a parry fracture (Figure 2), also known as a defence fracture since it is usually the consequence of a blow to the ulna when lifting the arm in a defence position (Mann \& Murphy, 1990; Smith, 1996). A radial fracture (Figure 3) and a Pott's fracture (Figure 4) were also noted. A sprinter's fracture was recorded in a male between 15 and 18 years of age (Figure 5). This is an avulsion fracture of the anterior inferior iliac spine caused by sudden strain on the rectus femoris muscle (Merbs, 1989).

Fractures to the skull comprised $49 \%(n=20)$ of observed traumatic injuries and were by far were the most frequently found in the sample. These included six healed fractures of the nasal bone, one of the orbital margin, four fractures of the zygomatic bone, four depressed fractures of the frontal bone (Figures 6 and 7) and five of the parietal bone. These lesions were all of relatively similar size and shape and are suggestive of blunt force trauma.

The limbs were the second most affected bone to present with fractures, particularly femoral fractures $(n=5,3 \%)$. Only one (1\%) tibial and two (1\%) fibular fractures were observed. The upper limbs were less affected than the lower limbs with the humerus $(n=1$, 
$1 \%)$, radius $(\mathrm{n}=2,1 \%)$ and ulna $(\mathrm{n}=2,1 \%)$ demonstrating 5 (1\% of investigated bones) fractures in total. No significant difference were observed between fractured bones of the upper or lower limbs $\left(\chi^{2}=0.502\right.$, $\mathrm{p}$-value $\left.>0.2\right)$. Furthermore four rib fractures, two fractured clavicles and one vertebral fracture was also observed.

\section{Spondylolysis and subluxation}

Spondylolysis, which refers to fracture of the vertebral arch resulting in bilateral separation of the pars interarticularis, was observed in $6 \%(n=7)$ of the sample (Table 4$)$. There was no significant difference in the occurrence of this lesion between the sexes $\left(\chi^{2}=\right.$ 0.001, p-value $>0.2$ ). All of the lesions showed bilateral separation of the neural arch (Figure 8) and occurred on L4 $(\mathrm{n}=3)$ and L5 $(\mathrm{n}=4)$. Spondylolysis associated with spondylolisthesis was seen in one individual (GLD NOP 3/4.1). These injuries are often associated with strenuous physical labour, and therefore were expected to be present among these diamond miners.

Another injury indicative of heavy, repetitive labour with little medical intervention would be longstanding subluxation of joints, which was noted in two individuals (Table 5). The first was in the right sternoclavicular joint of individual GLD S2.6, resulting in remodelling and the formation of an articulation facet on the inferior surface of the sternal end of the clavicle. The second was found in a 40 to 55 year old male (GLD N74.5). A fracture of the left humerus was most likely the cause for this subluxation. The nonreduced fracture caused shortening of the humeral shaft as well as lateral rotation of the distal end of the humerus. In order to attain some functionality of the arm, subluxation of the shoulder joint occurred (Figure 9). The subluxation caused a false articulation facet to develop between the acromion and the posterior surface of the humeral head. This most probably led to an unstable shoulder joint, with the humerus in a position of hyperextension and posterolateral rotation.

\section{Amputations}

While the dislocation of joints may have not received immediate care, evidence of medical intervention was noted in this sample with 6 individuals exhibiting healed and unhealed 
amputations. This included one amputation through the femur, two through the tibia and fibula, one of the foot at the ankle, one through the humerus and one through the proximal radius and ulna (Table 5).

A 30 - 35 year old male (GLD N38.2) presented with an amputation of the right femur, about $106 \mathrm{~mm}$ from the proximal end (Figure 10). This person did not survive the procedure, as the amputated limb was buried with the individual and the amputation showed no indication of healing. The reason for the amputation had most likely been a compound fracture of the distal femur (as observed during analyses of the remains) that had become severely infected, as indicated by the infectious new bone growth present around the fracture.

Examples of well-healed amputations included an amputation of the left tibia, fibula and foot (GLD N34.3) just distal to the proximal end of the left tibia and fibula (Figure 11), as well as an amputation of the left foot (GLD S2.6). These amputations developed into the very characteristic peg shape associated with healed amputations, accompanied by closure of the medullary cavity (Mann \& Murphy, 1990). Ankylosis of the distal ends of the left tibia and fibula occurred, following amputation of the foot.

Apart from the above-mentioned individuals who showed signs of amputations, three amputated limbs were excavated. These amputations were of great interest, since some yielded information regarding the reason for the procedure.

The first amputated limb was composed of a left tibia, fibula and foot amputated just distal to the knee (GLD N1.8(b)). The limb was found in a coffin with the complete skeleton of a 15 to 19 year old female. The cause for this amputation was severe infection of the lower leg, which had most likely commenced at the foot. Serious signs of infection with extensive remodelling and new bone formation of the left talus and calcaneus were observed along with signs of infectious new bone formation on the tibia and fibula. A radius and ulna, amputated just distal to the elbow (GLD S2.7c), was also recorded. Signs of infectious new bone formation were present on the proximal half of the bones. The last amputated element was a humerus (GLD S2.7b). This fragment of bone was amputated at both the distal and proximal ends, as can be seen in Figure 12. The initial distal amputation 
had most likely become infected shortly after the procedure was done and the amputation was accordingly extended proximally.

\section{Discussion}

\section{Evidence of interpersonal violence and strenuous activity among $19^{\text {th }}$ century migrant labourers}

The sample comprised of individuals who passed away at the surrounding hospitals in Kimberley and a high prevalence of pathologies, in general, can accordingly be expected. The frequency of disease in this sample should therefore be interpreted with caution, since it is not representative of a "healthy" group.

The assessment of healed trauma, such as the fractures observed in this study, on the other hand, can give a more accurate view into the lives of the people from which the sample came, since these lesions were not the reason for hospitalization. The frequency and various types of fractures within a population can yield important information regarding their lifestyle, their interaction with the environment as well as the nature of medical attention that was available at the time (Steinbock, 1976; Kilgore et al., 1997). Parry fractures of the ulna, blunt trauma to the skull and evidence of cut marks by a sharp object are all indicative of interpersonal violence (Smith, 1996; Jurmain \& Bellifemine, 1997; Kilgore et al., 1997; Lovell, 1997; Jurmain, 2001; Ortner, 2003; Judd, 2004). Femoral, tibial and humeral fractures, on the other hand, are usually related to accidental incidents such as falls (Kilgore et al., 1997).

The high prevalence of cranial fractures within this population (24\%) is suggestive of interpersonal violence, as was also suggested in a samples from Chile, where $24.6 \%(n=17)$ of individuals presented with cranial fractures (Standen \& Arriaza, 2000). Most of the fractures observed on the cranial vaults were circular in shape, relatively similar in size and seemed to have been caused by a weapon such as a knobkerrie, although this cannot be said with any certainty. A knobkerrie is a traditional South African weapon in the form of a club or stick with a rounded end at one side. All cranial fractures were due to blunt-force trauma and several other weapons or even rocks can produce the same skeletal results (Jurmain \& Bellifemine, 1997). Therefore, it should also be considered that the high prevalence of 
cranial fractures may be partly related to mining accidents such as rock falls, which were recorded in archival documents, and can not be exclusively attributed to interpersonal violence.

The incidence of lesions suggesting interpersonal violence concurred with historical documentation of violence amongst the black labourers in Kimberley. The notion of violence as a symbol of masculinity and group affiliation was very strong in this population, leading to fights between various groups. These fights were a means by which leaders were selected and justice was served. An Anglican clergymen reported that "tribal fights and murders occurred every weekend” (Harries, 1994: 58). According to records, weapons such as knobkeries, fighting sticks and pick handles were used (Harries, 1994).

Levels of interpersonal violence have been shown to increase when periods of environmental deterioration, sudden population growth and an increase in competition for resources are present within the population (e.g., Torres-Rouff \& Costa Junqueira, 2006). The discovery of diamonds in Kimberley was a catalyst for the creation of these conditions. Numerous individuals went to Kimberley to seek their fortune, or employment, causing a dramatic growth in population numbers (Roberts, 1976; Harries, 1994). When considering that the study sample was most likely migrant labourers from various parts of the country, aggressive behaviour may have also been spurred by cultural differences (Harries, 1994). Furthermore, the increase in population numbers would inevitably have caused competition for resources, especially among the labourers of lower socio-economic status. The high incidence of scurvy reported in archival documents for this population supports a state of limited nutritional resources (Van der Merwe, 2007). Few women were present in Kimberley, as suggested by the few female skeletons excavated as well as the archival records, and this fact may have increased the level of social conflict and competition. Other factors such as the regular over-indulgence in liquor, labour disputes and skirmishes over the theft and illegal selling of diamonds, all led to various violent confrontations between labourers and their employers or overseers (Turrell, 1987; Harries, 1994).

According to Lovell (1997), high fracture risks are associated with occupations generally restricted to men, such as agriculture, mining and forestry while domestic activities in developing countries (such as carrying water and firewood) also pose a high 
risk of fractures to females. Mining accidents occurred frequently in Kimberley. These included individuals falling down mine shafts, getting killed in rock falls, drowning in mud rushes and being run over with wagons, carts or trams, to name but a few (Cape of Good Hope Votes and Proceedings of Parliament 1901; Knight, 1978; Turrell, 1987; Harries, 1994). Thus the prevalence of long bone fractures, spondylolysis, longstanding subluxations as well as some of the cranial fractures within the Gladstone population are a reflection of the high-risk environment to which these individuals were subjected.

Separation of the neural arch or spondylolysis is a condition mostly recognized by the bilateral fracture of the pars articularis of L4 or L5 (Merbs, 1989; Arriaza, 1997). Lane (1893) noted that spondylolysis is associated with strenuous physical activity and stated that it occurs frequently in "people doing heavy labour".

An investigation into the incidence of this condition among 372 Black South Africans skeletons from the Raymond Dart collection was conducted by Eisenstein (1978), who found that 3\% of the sample population presented with spondylolysis (Eisenstein, 1978). Unfortunately the exact number of individuals presenting with the condition, as was observed by Eisenstein (1978), was not stated in the literature making statistical comparison difficult. The observed prevalence of the condition in the Gladstone sample (6.5\%) does, however, seem higher than what would be expected in the South African black population.

Spondylolysis is caused by increased compression of the posterior elements of the vertebrae due to hyperextension of the back, or increased shearing forces due to repeated flexion. During hyperextension of the back, the joints of adjacent vertebrae become locked together, causing an increase in stress exerted on the bone (Arriaza, 1997). The reason for the high prevalence of spondylolysis in this population is clear. Activities associated with open mining will include a higher-than-average incidence of hyperflexion and hyperextension of the back. This will inevitably increase the likelihood of spondylolysis in individuals who are susceptible (Earl, 2002; Lovell, 1997). The relatively high incidence of spondylolysis within this sample is thus suggestive of participation in the strenuous physical activities most likely associated with mining. While the prevalence of spondylolysis is stated to be higher in males than females (Arriaza, 1997; Lovell, 1997), no 
significant inter-sex difference was found in this study. However, this may be partly or wholly due to sample size and/or distribution.

It can therefore be concluded that the individuals within this sample was exposed to high levels of interpersonal violence, a hazardous working environment as well as strenuous labour requirements.

\section{Medical care in at the close of the $19^{\text {th }}$ century in Kimberley}

The clear evidence of saw marks perpendicular to the long axis of the bone observed on the amputated limbs supports the assertions made in historical documents that the Gladstone cemetery was used as a burial ground by Kimberley and other surrounding Hospitals. Several archival documentations of amputations are available from the Kimberley Hospital (Cape of Good Hope Votes and Proceedings of Parliament, 1885). According to these records, up to 35 amputations were done a year, which amounted to approximately 50\% of all operations performed in Kimberley Hospital (Cape of Good Hope Votes and Proceedings of Parliament, 1885). The operations were most likely done under general anaesthesia. Anaesthesia with ether was first performed in Grahamstown (South Africa) in June 1847, and by the 1850's chloroform was being used (Laider \& Gelfand, 1971). Unfortunately, no documentation suggesting the possible reasons for these amputations was available. However, two therapeutic reasons for the amputation of a limb can be suggested: the first is amputation after injury, resulting from such severe crushing of the limb that had no chances of healing. When considering the types of mine accidents reviewed earlier, crushing and compound fractures such as these may have been frequently encountered in Kimberley. The second reason for amputation is severe infection of a part of a limb. The evidence of infectious lesions found on amputated limbs (such as GLD N38.2, GLD N8.1b, GLD S2.7b and GLD S2.7c) suggests that some amputations were a result of severe infections. This is plausible in light of the fact that antibiotics were not yet available for the treatment of infectious conditions (Quetel, 1990). The amputation of the infected body part was thus the only way to prevent spreading of the infection.

The presence of some well healed and remodelled fractures within this population also indicates that medical care, although sometimes limited, was available in the situation of a 
fracture. This has been confirmed historically, since hospital records refer to the treatment of injuries, which most likely would have included fractures (Cape of Good Hope Votes and Proceedings of Parliament, 1899; Cape of Good Hope Votes and Proceedings of Parliament, 1900).

In summary, the high prevalence of cranial fractures within this population is suggestive of high levels of interpersonal violence (Jurmain \& Bellifemine, 1997; Standen \& Arriaza, 2000). Cultural differences amongst migrant workers, competition for resources, few females, regular overindulgence in alcohol, and labour issues all most likely contributed to the occurrence of violent events within and amongst labourers and their employers (Harries, 1994; Turrell, 1987).

The incidence of fractures of long bones and possibly some of the cranial fractures, as well as the presence of spondylolysis and longstanding subluxations are indicative of the strenuous work and high-risk environment these individuals were exposed to. Medical treatment was available to these individuals, bearing in mind the presence of well reduced fractures and evidence of amputation for medical purposes.

This study has provided a valuable glimpse into the working environment, social situation and medical facilities in Kimberley at the close of the $19^{\text {th }}$ century. More than 14 million carats of diamonds were extracted from a hole with an outside diameter of $1200 \mathrm{~m}$, approximately $800 \mathrm{~m}$ deep, which used to be Colesberg Kopje. This research offers recognition to those unnamed labourers who unknowingly played a crucial role, not only in the history, but also in the economic growth of South Africa.

\section{Acknowledgements}

We would like to thank the local community as well as David Morris and the McGregor Museum in Kimberley for allowing us the opportunity to study the remains, and are greatly indebted towards M. Klemp for her help and hospitality. Funding was through the National Research Foundation (NRF) and NAVKOM. 


\section{References}

Asala SA. 2001. Sex determination from the head of the femur of South African whites and blacks. Forensic Science International 117: 15-22.

Arriaza BT. 1997. Spondylolysis in prehistoric human remains from Guam and its possible etiology. American Journal of Physical Anthropology 104: 393-397.

Auferheide AC and Rodríguez-Martin C. 1998. The Cambridge Encyclopedia of Human Paleopathology. Cambridge University Press: Cambridge, UK.

Brothwell D and Møller-Christensen V. 1963a. A possible case of amputation dated to c.2000 BC. Man 58: 192-194.

Brothwell D and Møller-Christensen V. 1963b. Medico-historical aspects of a very early case of mutilation. Danish Medical Bulletin 10: 21-25.

Cape of Good Hope Votes and Proceedings of Parliament 1885, Hospitals and Asylums report for the years 1884 G10 Appendix I.

Cape of Good Hope Votes and Proceedings of Parliament 1899, Hospitals and Asylums Report for 1898 Appendix I.

Cape of Good Hope Votes and Proceedings of Parliament 1901, Hospitals and Asylums Report for 1900 Appendix I.

De Villiers H. 1968. Sexual dimorphism of the skull of the South African Bantu-speaking Negro. South African Journal of Science 84: 118-124.

Earl JE. 2002. Mechanical aetiology, recognition, and treatment of spondylolithesis. Physical Therapy in Sport 3: 79-87.

Franklin D, Freedman L and Milne N. 2005. Sexual dimorphism and discriminant function sexing in indigenous South African crania. HOMO 55: 213-228.

Eisenstein SM. 1978. Spondylolysis: A skeletal investigation of two population groups. Journal of Bone and Joint Surgery 60-B(4): 488-494.

Glencross B and Stuart-Macadam P. 2000. Childhood trauma in the archaeological record. International Journal of Osteoarchaeology 10: 198-209.

Grauer AL and Roberts CA. 1996. Paleoepidemiology, healing, and possible treatment of trauma in the medieval cemetery population of St. Helen-on-the-walls, York. England. American Journal of Physical Anthropology 100: 531-544. 
Harries P. 1994. Work, culture and identity. Migrant laborers in Mozambique and South Africa, c 1860 - 1910. Witwatersrand University Press: Johannesburg.

Hillson S. 1998. Dental Anthropology. Cambridge University Press: United Kingdom.

Judd M. 2004. Trauma in the city of Kerma: Ancient versus modern injury patterns. International Journal of Osteoarchaeology 14: 34-51.

Jurmain R. 2001. Palaeoepidemiological patterns of trauma in a prehistoric population from Central Calafornia. American Journal of Physical Anthropology 115: 13-23.

Jurmain R and Bellifemine VI. 1997. Patterns of cranial trauma in a prehistoric population from Central California. International Journal of Osteoarchaeology 7: 43-50.

Kilgore L, Jurmain R and Van Gerven D. 1997. Palaeoepidemiological patterns of trauma in a medieval Nubian skeletal population. International Journal of Osteoarchaeology 7: 103-114.

Knight BH. 1978. Injuries sustained in mining and quarrying. In The pathology of Violent Injury. Mason JK (ed.). 137 - 150 Edward and Arnold: London

Krogman WM and İşcan MY. 1986. The human skeleton in forensic medicine, 2nd edn. Charles C Thomas: Springfield, Illinois.

Laidler PW and Gelfand M. 1971. South Africa: its medical history. 1652 - 1898 Struik: Cape Town.

Lane A. 1893. Case of Spondylolythesis associated with progressive paraplegia: laminectomy. The Lancet 1:991-992.

Larsen CS. 1997. Bioarchaeology. Interpreting behavior from the human skeleton. Cambridge University Press: Kingdom.

Lovejoy CO and Heiple KG. 1981. The analysis of fractures in skeletal population with an example from the Libben site, Ottowa Count, Ohio. American Journal of Physical Anthropology 55: 529-541.

Lovell NC. 1997. Trauma analysis in paleopathology. Yearbook of Physical Anthropology 40: $139-170$.

Mann RW and Murphy SP. 1990. Regional Atlas of Bone Disease, A Guide to Pathologic and Normal Variation in the Human Skeleton. Charles C Thomas: Springfield.

Merbs CF. 1989. Trauma. In Reconstruction of Life from the Human Skeleton. İşcan MY and Kennedy KAR. (ed.). 161-190 Alan R. Liss, Inc. 
Merbs CF. 2002. Asymmetrical spondylolysis. American Journal of Physical Anthropology 119: 156-174.

Neri R and Lancellotti L. 2004. Fractures of the lower limbs and their secondary skeletal adaptations: a 20th century example of pre-modern healing. International Journal of Osteoarchaeology 14: 60-66.

Oettlé C and Steyn M. 2000. Age estimation from sternal ends of ribs by phase analysis in South African blacks. Journal of Forensic Sciences 45(5):1071-1079.

Ortner DJ. 2003. Identification of pathological conditions in human skeletal remains, 2 edn. Academic Press: Amsterdam.

Pietrusewsky M, Douglas MT and Ike-Quebral RM. 1997. An Assessment of health and disease in the Prehistoric inhabitants of the Mariana Islands. American Journal of Physical Anthropology 104: 315-342.

Roberts B. 1976. Kimberley Turbulent City. Pioneer Press (PTY) LTD: Capetown.

Roberts C and Manchester K. 1995. The Archaeology of Disease, 2 edn. Alan Sutton Publishing Limited: United Kingdom.

Smith MO. 1996. 'Parry' fractures and female-directed interpersonal violence: Implications from the later archaic period of west Tennessee. International Journal of Osteoarchaeology 6: 84-91.

Standen VG and Arriaza BT. 2000. Trauma in the pre-ceramic Coastal population of Northern Chile: Violence or occupational hazards? American Journal of Physical Anthropology 112: 239-249.

Steinbock RT. 1976. Paleopathological Diagnosis and Interpretation. Charles C. Thomas publishers: Springfield.

Stirland AJ. 1996. Patterns of trauma in a unique medieval Parish cemetery. International Journal of Osteoarchaeology 6: 92-100.

Stoney WW. 1900. Report of the Medical Officer of Health, Kimberley, for the year 1898.

Torres-Rouff C and Costa Junqueira MA. 2006. Interpersonal violence in prehistoric San Pedro de Atacama, Chile: Behavioral implications of environmental stress. American Journal of Physical Anthropology 130: 60-70.

Turrell RV. 1987. Capital and Labour on the Kimberley Diamond Fields 1871 - 1890. Cambridge University Press: Cambridge. 
Van der Merwe AE. 2007. Human Skeletal Remains from Kimberley: An Assessment of Health in a 19th Century Mining Community, Unpublished M.Sc. Thesis, University of Pretoria.

Walker PL. 2001 A bioarchaeological perspective on the history of violence. Annual review of Anthropology 30:573 - 596. 
Table 1. Number of individuals with fractured bones observed in the Gladstone skeletal sample

\begin{tabular}{|lccc|}
\hline & $\mathrm{N}$ & $\mathrm{Nf}$ & $\%$ \\
\hline Males & 86 & 24 & 27,9 \\
Females & 15 & 4 & 26,7 \\
Total & 101 & 28 & 27,7 \\
\hline
\end{tabular}

$\mathrm{N}$ - number of individuals examined

$\mathrm{Nf}$ - number of individuals who presented with one or more fractures 
Table 2. The number of skeletal elements fractured in the Gladstone skeletal sample

\begin{tabular}{|lccccccccccc|c|}
\hline & $\mathrm{S}$ & $\mathrm{Fe}$ & $\mathrm{Ti}$ & $\mathrm{Fi}$ & $\mathrm{Oc}$ & $\mathrm{Ra}$ & $\mathrm{Ul}$ & $\mathrm{Hu}$ & $\mathrm{Cl}$ & $\mathrm{Ri}$ & $\mathrm{Vb}$ & Total \\
$N$ & 84 & 181 & 173 & 166 & 161 & 164 & 164 & 169 & 159 & $* *$ & $* *$ & \\
Males & 12 & 4 & 1 & 2 & 1 & 2 & 2 & 1 & 1 & 4 & 1 & 31 \\
Females & 3 & 1 & 0 & 0 & 0 & 0 & 0 & 0 & 1 & 0 & 0 & 5 \\
\hline Total & 15 & 5 & 1 & 2 & 1 & 2 & 2 & 1 & 2 & 4 & 1 & 36 \\
\hline$\%$ & 17,9 & 2,8 & 0,6 & 1,2 & 0,6 & 1,2 & 1,2 & 0,6 & 1,3 & $* *$ & $\star *$ & \\
\hline
\end{tabular}

$\mathrm{N}$ - Number of skeletal elements investigated

** Due to the fragmentary condition of ribs and vertebrae, the total number of elements could not determined. S - Skull; Fe - femur; Ti - tibia; Fi - fibula; Oc - Os coxa; Ra - radius; Ul - Ulna; Hu - humerus; $\mathrm{Cl}$ - clavicle; $\mathrm{Vb}$ - vertebra; $\mathrm{Ri}$ - rib. 
Table 3 The prevalence of fractures in the Gladstone sample

\begin{tabular}{|c|c|c|c|c|c|c|c|c|c|c|c|c|}
\hline Number & Sex & Age (years) & Fractures* & $S$ & $\mathrm{Fe} \mathrm{Ti}$ & $\mathrm{i} \mathrm{Fi} \mathrm{C}$ & Oc & $\mathrm{Ra}$ & $\mathrm{Ul}$ & & & $\mathrm{Ri} \mathrm{Vb}$ \\
\hline GLD N31.E.1 & Male & $30-40$ & 3 & 3 & & & & & & & & \\
\hline GLD N74.2 & Male & $18-21$ & 1 & 1 & & & & & & & & \\
\hline GLD N74.5 & Male & $40-55$ & 1 & & & & & & & 1 & & \\
\hline GLD N100.2 & Male & $28-38$ & 1 & & & & & & & & 1 & \\
\hline GLD S1.2 & Male & $25-35$ & 1 & 1 & & & & & & & & \\
\hline GLD N100.1 & Male & $40-55$ & 1 & 1 & & & & & & & & \\
\hline GLD N34.3 & Male & $30-35$ & 2 & 2 & & & & & & & & \\
\hline GLD N34.5 & Male & $15-18$ & 1 & & & & 1 & & & & & \\
\hline GLD N34.6 & Male & $22-28$ & 1 & 1 & & & & & & & & \\
\hline GLD N34.9 & Male & $22-30$ & 1 & 1 & & & & & & & & \\
\hline GLD N34.12 & Male & $22-30$ & 1 & 1 & & & & & & & & \\
\hline GLD N38.1 & Male & $23-30$ & 1 & & & & & & & & & 1 \\
\hline GLD N38.2 & Male & $25-29$ & 4 & 1 & 11 & 1 & & & & & & \\
\hline GLD N38.3 & Male & $30-40$ & 2 & & & 1 & & 1 & & & & \\
\hline GLD N74.6 & Male & $30-45$ & 3 & 2 & & & & & & & & 1 \\
\hline GLD N74.4 & Male & $30-40$ & 1 & & & & & & 1 & & & \\
\hline GLD N8.2 & Male & $25-30$ & 1 & & & & & & & & & 1 \\
\hline GLD N8.10 & Male & $20-25$ & 1 & 1 & & & & & & & & \\
\hline GLD S2.3 & Male & $20-25$ & 2 & & 1 & & & 1 & & & & \\
\hline GLD S2.9 & Male & $35-45$ & 2 & & 1 & & & & & & & 1 \\
\hline GLD S3.2 & Male & $30-40$ & 1 & & & & & & & & & 1 \\
\hline GLD S3.5 & Male & $25-30$ & 1 & & 1 & & & & & & & \\
\hline GLD S5.1 & Male & $28-34$ & 2 & 2 & & & & & & & & \\
\hline GLD SE7.9 & Male & $35-45$ & 1 & & & & & & 1 & & & \\
\hline \multicolumn{3}{|c|}{ Total number of fractures in males } & 36 & 17 & $4 \quad 1$ & 2 & 1 & 2 & 2 & 1 & 1 & $4 \quad 1$ \\
\hline GLD SE11.6 & Female & $30-37$ & 1 & & 1 & & & & & & & \\
\hline GLD N74.1 & Female & $40-50$ & 1 & 1 & & & & & & & & \\
\hline GLD S2.4 & Female & $33-43$ & 2 & 1 & & & & & & & 1 & \\
\hline GLD SE7.5 & Female & $30-43$ & 1 & 1 & & & & & & & & \\
\hline \multicolumn{3}{|c|}{ Total number of fractures in females } & 5 & 3 & 10 & 0 & 0 & 0 & 0 & 0 & 1 & $0 \quad 0$ \\
\hline \multicolumn{3}{|c|}{ Total number of fractures in sample } & 41 & 20 & t & 2 & 1 & 2 & 2 & 1 & 2 & \\
\hline
\end{tabular}

${ }^{*}$ The number of fractures observed per individual;

S - Skull; Fe - femur; Ti - tibia; Fi - fibula; Oc - Os coxa; Ra - radius; Ul - Ulna; Hu - humerus; Cl - clavicle; Vb - vertebra; Ri - rib. 
Table 4. The prevalence of spondylolysis and subluxation in the Gladstone population

\begin{tabular}{|l|l|l|c|c|}
\hline Number & sex & age(years) & Spondylolysis & Subluxation \\
\hline GLD N31.E.1 & male & $30-40$ & 1 & \\
GLD N74.3 & male & $17-22$ & 1 & \\
GLD N74.8 & male & $16-20$ & 1 & \\
GLD N74.5 & male & $40-55$ & 1 & 1 \\
GLD N34.8 & female & $20-23$ & 1 & \\
GLD N34.4 & male & $18-21$ & & \\
GLD N34.6 & male & $22-28$ & & \\
GLD N38.3 & male & $30-40$ & & \\
GLD N74.7 & male & $35-50$ & 1 & \\
GLD NOP 3/4.1 male & $25-35$ & 1 & \\
GLD S2.6 & male & $35-45$ & & 1 \\
\hline Total n $=107$ & & & 7 & 2 \\
$\%$ & & & 6.5 & 1.8 \\
\hline
\end{tabular}

$\mathrm{n}$ - total number of individuals investigated 
Table 5 The incidence and location of amputations

\begin{tabular}{|c|c|c|c|c|c|c|c|c|c|}
\hline Number & Sex & Age(years) & Femur & \begin{tabular}{|l} 
Tibia \& \\
Fibula
\end{tabular} & Foot & Humerus & \begin{tabular}{|l} 
Ulna \& \\
Radius
\end{tabular} & Total & $\%$ \\
\hline GLD N34.3 & Male & $30-35$ & & 1 & & & & & \\
\hline GLD N38.2 & Male & $25-29$ & 1 & & & & & & \\
\hline GLD & & & & & & & & & \\
\hline N8.1amp & Male & Adult & & 1 & & & & & \\
\hline GLD S2.6 & Male & $35-45$ & & & 1 & & & & \\
\hline GLD S2.7b & Unknown & Unknown & & & & 1 & & & \\
\hline GLD S2.7c & Unknown & Unknown & & & & & 1 & & \\
\hline Total $\mathrm{n}=107$ & & & 1 & 2 & 1 & 1 & 1 & 6 & 5.6 \\
\hline
\end{tabular}

